\title{
Seminar Hall Automation using Microcontroller
}

\author{
Bhusare Gayatri ${ }^{1}$, Zade Mohini ${ }^{2}$, Pawar Yograni ${ }^{3}$, Mr. Kiran P. Varade ${ }^{4}$ \\ ${ }^{123}$ BE Student, Department of Electrical Engineering SVIT College Of Engineering Chincholi Nashik Maharashtra India \\ ${ }^{4}$ Association Professor Department of Electrical Engineering Chincholi Nashik Maharashtra India.
}

\begin{abstract}
In seminar hall automation system different system technologies are employed for conservation of electricity. Electricity is one of the most important resources int this century. We should conserve electricity otherwise next generation may have to live without electricity but many times we can forgot to turn off the lights and fans when we comes outsides the hall. And thus electricity is wasted.

Also in most of the cases switches of the light and fan are located inside the room and so have to search them in darkness. To overcome this issue and for conservation of electricity we planned a project in two parts. First one is "Person Counter" and other one is "Automatic Room Light \& Temperature Controller with a Temperature \& Light Intensity Display “. The $1^{\text {st }}$ part is to count the no of person/ visitors entering or leaving the hall \& it display on the LCD. From this we decide the no. of seats remaining in large room like seminar hall ; conference hall etc. when the no person enter the room is zero then power supply inside the room the system automatically measures the room temperature; light intensity ; automatic ON/OFF the fan inside the room . During day time lights not be operated \& during cold season fan may not be operated. This efforts LCD also display temperature and light intensity.
\end{abstract}

Key Words: Automation, Person counter, TRAIC, PIC

\section{INTRODUCTION}

Energy crisis is the main problem that we facing nowadays. So the conservation of energy is relevant in this occasion. Th main objectives of this project is to overcome this problem. This project has 2 parts. The first is "person counter "and the one is an "Automatic room light and temperature controller with the increase in standard of living, there is a need for developing technique that would ease the involution of life. The temperature and light intensity in the room is sensed and with respect to that, light and fan in the room is switched ON/OFF when a person enters/ leaves the room. The circuits consists of IR transmitter and receiver LEDs which are used to sense the entering or leaving of a person to or from the room. The temperature sensor measures the temperature inside the room and analog signal from the sensor is processed by the microcontroller. Likewise the light

Dependent resisters (LDR) generates the analog signals proportional to the available light inside the room. This signal is also processed by microcontroller. Whenever the person leaves the room, light and fan will switched OFF. The speed of the fan and brightness of the light is controlled accordingly. The circuits which we have designed is simple and compact. This Project is a microcontroller based room automation. The total number of person inside the room is also displayed on the seven segment display.

\subsection{Definition}

Automation means a technology that performed various procedure this procedure required minimum human contribution. Automation has been achieved by various way like mechanical, hydraulic, electrical, and electronics etc. Can complete the task where a high degree of accuracy is required. The way of automation work that contains higher production band and also increased productivity and more efficient use of material, civilize product, improved rescue, less workweeks for labors, worker safety is important in automation.

The use of largely automatic equipment in system of manufacturing or other production process. Simply put Robotic Process Automatic (RPA) is the process of automatic your current work flows so any of your work flow that you have, probably can automate. It's a technology that controls all the process with the help of automation means using the various electronics devices that help in reducing the human work. Also a mechanical devices are operated electronically and that function are done automatic without giving a continuous input from an worker this process or procedure of automating.

\subsection{Aim of Project}

Energy conservation is the need for future. Today's world energy crisis is the main problem that we are facing. The aim of this project is to solve this problem and save the energy and it also reduced the human efforts with the help of automation.

\section{BLOCK DIAGRAM \& DISCRIPTION}

In this project an automatic room light $\&$ fan system is develop using microcontroller. The main component of the project is IR sensors and we have used to them of the placement of the sensors is important as it will determining the functioning of the project. These IR sensors are connected to the microcontroller. Controller count the person entering and leaving the room. LCD is used to display the number of persons in the hall. The power supply is required is provided by either Solar Panel or by using wind Mills. Battery is provided in between solar panel and supply. The required energy is stored in battery which is used by power supply whenever required.

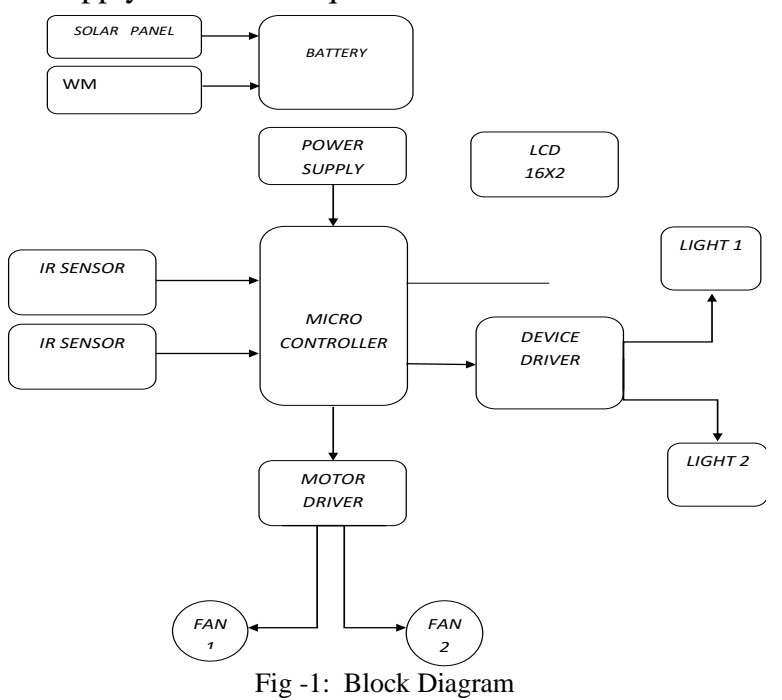




\section{A. MAIN COMPONENTS \& DISCRIPTION}

- Pic controller

- Display/LCD

- Sensors

- Power supply

- DC motor

- Device drivers

\subsection{PIC CONTROLLER}

Microcontroller PIC16F877 essentially consist of timers, counters, and input/output ports, analog to digital converters (ADC). The components like IR sensors, LM35, LCD display are connected to the controller. Controller count the person in and out to the room and display on LCD.

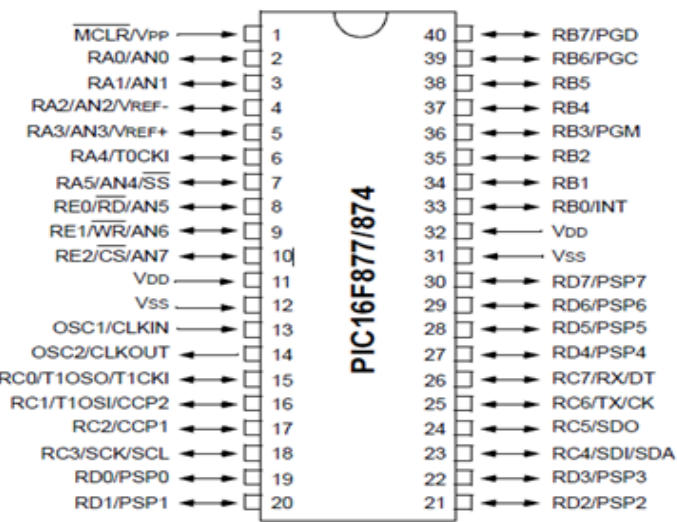

Fig -2: PIC Diagram

\section{$2.2 L C D$}

LCD means liquid crystal display we use this device because of it's a technology that display on screen this is generally used in laptop computer screen, and also mobiles, TVs, video games also.

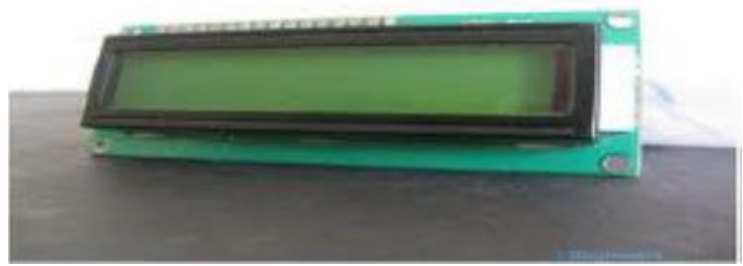

Fig -3: LCD Diagram

\subsubsection{TEMPERATURE SENSOR}

LM35 temperature sensors are used in this experiment. LM35 IC is used as the temperature sensor. It consist of three pins. For every 1degree variation in the room temperature, there will be a variation in the output voltages of this IC. This analog signal output will be given to the microcontroller for further processing and controlling. The room temperature will be display in the LCD.

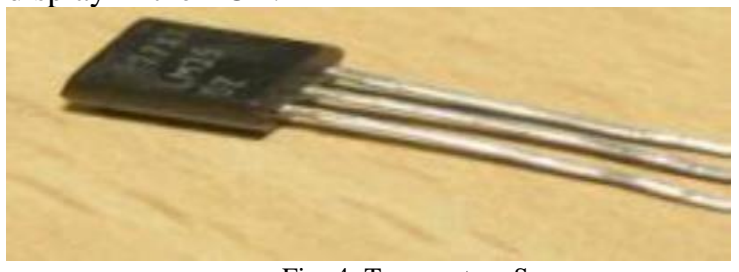

Fig -4: Temperature Sensor

\subsubsection{IR SENSOR}

IR sensors used as input circuit. One IR sensor pair is fitted on in door and one is fitted on our door. These IR sensor will check the persons coming in and out of the hall. These are connected to the microcontroller. Controller counts the in person and the out persons.

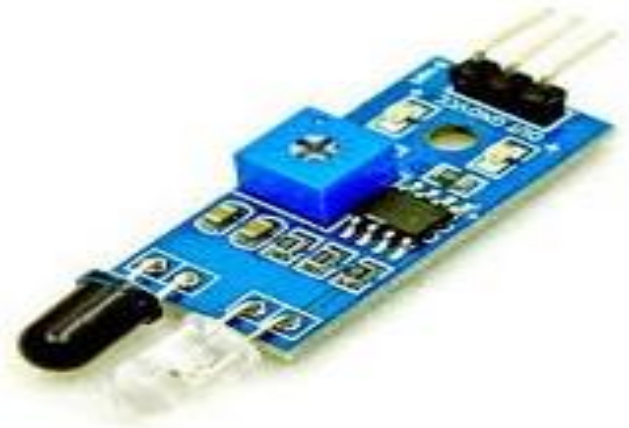

Fig -5: IR Sensor

\section{CONCLUSIONS}

This project is work on the seminar hall automation. In this system the energy consumption is developed. User comes into the hall or leaves the hall the lights and fans are automatically on/off User can reduce their electricity bill.

This system is easy to operate and control. And also a cost effective system. We can implemented this system in malls, schools etc. It reduces the human efforts. For future scope we can add camera to the system.

\section{ACKNOWLEDGEMENT}

I feel great pleasure to present the dissertation entitled as "SEMINAR HALL AUTOMATION USING MICROCONTROLLER" but it would be unfair on our part if we do not acknowledge efforts of some of the people, without the support of whom this work would not have been a success.

Very first I am greatly to my respected project guide MR. Kiran $P$ Varade Assistant Professor of Electrical Engineering Department for permitting me to use the all available facilities foe successful work od dissertation.

I would like to express my sincere gratitude to respected Prof. Nadeem B shaikh, HOD of Electrical Engineering Department, \& Dr. Mukesh K Kumawat Project Coordinator \& Prof. (Dr). Y. R. Kharde Principal of SVIT, Chincholi for finding out time and helping me in this project work.

I am also thankful to all Teaching and Non-Teaching Staff member of Electrical Engineering department who has helped me directly or indirectly during this work.

Last but not least I wish to express my gratitude to my loving parents and friends and all well-wishers for their moral support during completion of this project work. 


\section{REFERENCES}

[1] Ying-Wen Bai and Yi- Te Ku, "Automatic Room Light Intensity Detection and Control Using a Microprocessor and Light Sensors", IEEE Transactions on Consumers Electronics, Vol. 54. NO. 3, AUGEST 2008

[2] Yong Tae Park, Pranesh Sthapit, Jae-Young Pyun, "Smart Digital Door Lock for the Homae Automation", SEPTEMBER2009

[3] Jonh-Paul H. Knauus, Cheri Warren, Dave Kearns, "An Innovativr Approach to Smart Automation Testing at National Grid", IEEE, May, 2012

\section{BIOGRAPHIES}

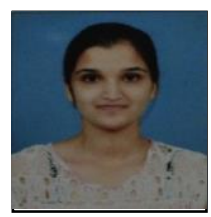

Bhusare Gayatri S.

U.G. Student, Electrical Engineering

SVIT, Nashik, Maharashtra, India.

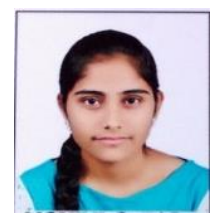

Zade Mohini B.

U.G. Student, Electrical Engineering SVIT, Nashik, Maharashtra, India.

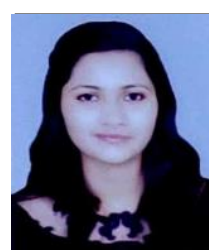

Pawar Yograni A.

U.G. Student, Electrical Engineering SVIT, Nashik, Maharashtra, India.

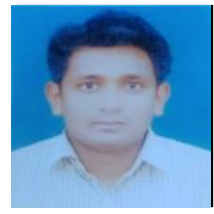

Prof. Kiran P. Varade, Assistant Professor of Electrical Engineering Dept., SVIT, Nashik, Maharashtra, India. 